\title{
A recepção crítica da obra de Adriana Lisboa
}

\author{
Neila Brasil Bruno* \\ Universidade Federal da Bahia \\ Salvador, Brasil \\ Recebido em: 30/04/2019 \\ Aceito em: 25/o7/2019
}

Resumo: Desenvolve-se, neste artigo, uma análise da recepção crítica da obra de Adriana Lisboa com o objetivo central de verificar qual a posição da crítica especializada e da crítica não especializada diante da produção literária da autora. Nesta investigação, buscou-se evidenciar as temáticas dos romances de Adriana Lisboa e apontar como a crítica tem contribuído para a criação de um público específico para esta escritora. Para isso, utilizamos como base de nosso trabalho estudos de autores como Pierre Bourdieu, para um aprofundamento sociológico das questões que envolvem a arte, e Tânia Pellegrini, para o entendimento da formação do campo crítico no Brasil, entre outros.

Palavras-chave: Adriana Lisboa. Recepção crítica. Profissionalização. Campo literário.

\begin{abstract}
This article analyzes the critical reception of the work of Adriana Lisboa with the main objective of verifying the position of specialized critic and non-specialized criticism before the author's literary production. In this investigation, we tried to highlight the themes of the novels of Adriana Lisboa and to point out how the criticism has contributed to the creation of a specific audience for this writer. For this, we use as basis of our work studies by authors such as Pierre Bourdieu, for a sociological deepening of issues involving art, and Tânia Pellegrini, for understanding the formation of the critical field in Brazil.
\end{abstract}

Keywords: Adriana Lisboa. Critical reception. Professionalism. Literary field.

Resumen: Se desarrolla en este documento, un análisis de la recepción crítica de la obra de Adriana Lisboa con el objetivo principal de encontrar cuál es la posición de los críticos y la crítica no especializados en la producción literaria del autor. En este estudio, hemos tratado de poner de relieve los temas de la novela Adriana Lisboa y señalar cómo la crítica ha contribuido a la creación de un público específico para el que escribe. Para ello, utilizamos como base de nuestro trabajo estudios de autores como Pierre Bourdieu, para una profundización sociológica de las cuestiones que envuelven el arte, y Tânia Pellegrini, para el entendimiento de la formación del campo crítico en Brasil. Palabras clave: Adriana Lisboa. Recepción crítica. Profesionalización. Campo literario. 


\section{Introdução}

Os textos que tratam da obra da escritora brasileira Adriana Lisboa formam uma fortuna crítica considerável. Boa parte desses textos é feita pela crítica especializada ou acadêmica, que tem produzido capítulos de livros, teses, dissertações e artigos acerca da autora, seu estilo ou sobre a sua imagem pública como escritora. Por outro lado, uma ampla gama de publicações, que podemos chamar de crítica jornalística ou não especializada, dá visibilidade à sua atividade de escritora. Essas publicações incluem artigos jornalísticos, entrevistas, textos em blogs, sites de literatura, postagens nas redes sociais, entre outros. Há ainda textos em que a própria autora torna-se crítica de sua literatura. Tendo isso em vista, neste artigo, pretendemos investigar se a recepção de sua obra colaborou para a formação de um público específico, e se isso, consequentemente, influenciou seu processo de profissionalização.

Para tanto, traçaremos o seguinte percurso metodológico. Em primeiro lugar, faremos algumas considerações sobre o funcionamento do campo literário, de acordo com a contribuição teórica de Pierre Bourdieu. Nosso interesse específico é caracterizar a crítica como uma instância legitimadora, que contribui para a construção da imagem dos escritores. Em seguida, faremos uma seleção de textos significativos sobre a obra de Adriana Lisboa que conduzam a reflexões sobre seu processo de profissionalização. Os trechos, fragmentos de artigos e notícias serão aqui citados e detalhados no corpo da seção. Por fim, estudaremos a relação entre as estratégias de escrita, ou seja, entre as estratégias ficcionais de Adriana Lisboa, e a imagem da autora moldada pela crítica.

Sabemos que a arte é afetada pelos meios de produção e que o funcionamento do campo literário está ligado às causalidades históricas, econômicas e sociais. As mudanças no campo social e os avanços tecnológicos alteram acentuadamente a forma como o artista, o público e a crítica passam a se inter-relacionar. O escritor contemporâneo está necessariamente inserido no mercado e sua remuneração é proporcionada pela venda de sua produção e pelas demais atividades correlatas ao seu papel do escritor. O modo de produzir e difundir suas obras interfere no lugar que ele ocupa no campo literário. 
É partindo deste pressuposto que intencionamos mostrar, a partir de uma investigação da fortuna crítica da obra de Adriana Lisboa, o modo como se dá o processo de legitimação da escritora e de sua produção no campo literário. Entendemos que o debate em torno das definições que situam a crítica em um campo "especializado" e outro "não-especializado" se encontra mais fluido, e que há discordância por parte de alguns teóricos na separação de dois campos distintos. Deste modo, levamos em consideração que tanto um como o outro contribui para a imagem de Adriana Lisboa como escritora profissional, sem deixar de levar em conta a especificidade de cada tipo de produção crítica em nossa análise.

O funcionamento da instância legitimadora pode ser explicado por meio das considerações levantadas por Pierre Bourdieu em A economia das trocas simbólicas (2013), livro no qual o autor apresenta a formação do mercado de bens culturais e simbólicos desde a Idade Média até a Idade Moderna, quando a produção cultural passa a ter autonomia. Um dos pontos que vale ser destacado em relação à formação desse mercado é a transformação das formas de produção a partir do advento da Revolução Industrial. Os bens culturais e a função que desempenham na sociedade também são transformados pelos novos meios de produção e circulação de mercadorias. Assim, Bourdieu expõe que:

A história da vida intelectual e artística das sociedades européias revelase através da história das transformações da função do sistema de produção de bens simbólicos e da própria estrutura destes bens, transformações correlatas à constituição progressiva de um campo intelectual e artístico, ou seja, à autonomização progressiva do sistema de relações de produção, circulação e consumo de bens simbólicos (BOURDIEU, 2013, p. 99).

Pode-se ter uma ideia do funcionamento do processo de legitimação literária tomando como exemplo a gênese do gênero romance e o percurso percorrido para sua legitimação no campo literário. Com o surgimento do folhetim, na segunda metade do século XIX, a prosa romântica se torna popular, angariando um vasto número de leitores. A partir de então, a opinião pública passa a ter um papel importante na apreciação crítica das obras literárias. Apesar de ter sofrido um rebaixamento de valor no período, no que diz respeito aos teóricos burgueses, devido ao seu caráter popular, o romance não diminuiu sua relevância no campo 
literário. Pelo contrário, o momento de transição entre a concepção da obra de arte como um bem consagrado e religioso e a valorização estética do objeto artístico foi o que oportunizou o início da autonomia do escritor e a democratização da leitura. O acesso à produção artística por parte da população possibilitou uma nova formatação crítica. Nas palavras de Bourdieu (2013, p. 100): "a vida intelectual e artística [...] libertou-se progressivamente, tanto econômica como socialmente, do comando da aristocracia e da Igreja, bem como de suas demandas éticas e estéticas".

Os modos e os meios que configuram essas mudanças não possuem um rumo definido, não sendo possível antever o que fará com que um conjunto de obras se torne relevante, isto é, não é possível determinar o que será bem recebido pela crítica. A ruptura com os princípios teóricos que regiam a esfera artística no século XVIII e começo do século XIX abre espaço para uma teoria do romance, integrando essa nova forma de escrita num sistema de formas estéticas que passa a ganhar legitimidade no campo teórico. Georg Lukács, ao apresentar o desenvolvimento do romance como epopeia burguesa, explica que:

\footnotetext{
Esta falta de interesse por aquilo que é especificamente novo no desenvolvimento burguês da arte não é evidentemente casual. Em todas as questões estéticas, o pensamento teórico da jovem burguesia devia forçosamente manter-se o mais possível próximo do seu modelo antigo, no qual encontrara uma afiada arma ideológica para sua luta pela cultura burguesa em oposição à cultura medieval. [...] Consequentemente, todas as formas da criação artística que não correspondiam aos modelos antigos e que se tinham originado organicamente da cultura medieval com semblante popular e às vezes até plebeu, são ignoradas pela teoria e frequentemente até recusadas como "não-artísticas" (LUKÂCS, 1999, p. 88).
}

Ao utilizarmos como exemplo a constituição do romance como gênero, compreendemos a contingência que acompanha o desenvolvimento da literatura e da crítica literária. Afetada pelo sistema de produção de massa e associada ao mercado, a literatura, assim como outras criações artísticas, obedece a determinações econômicas. Pode-se afirmar que a crítica que se dirige à produção literária tornou-se multifacetada, abrangendo diversos sistemas de legitimação. Bourdieu chama atenção para 
[...] a multiplicação e a diversificação das instâncias de consagração competindo pela legitimidade cultural, como por exemplo as academias, os salões [...], e das instâncias de difusão cujas operações de seleção são investidas por uma legitimidade propriamente cultural, ainda que, como no caso das editoras e das direções artísticas dos teatros, continuem subordinadas a obrigações econômicas e sociais capazes de influir, por seu intermédio, sobre a própria vida intelectual (BOURDIEU, 2013, p. 100).

Apesar da diversificação das instâncias de consagração competindo pela legitimidade cultural, causada em parte pelas transformações econômicas e pela forma com que os bens culturais passam a ser difundidos, isso não pressupõe o aniquilamento da teoria e da crítica literária e sim o oposto. Esse cenário contribuiu para a elaboração de uma teoria da arte desvinculada do mercado, para que houvesse a distinção entre o campo de produção erudito e o campo de produção industrial. A constituição da obra de arte como mercadoria e o fortalecimento de uma categoria particular de produtores de bens simbólicos destinados ao mercado permitiram uma dissociação entre arte como mercadoria e arte como pura significação, destinada à fruição desinteressada (BOURDIEU, 2013, p. 103).

Havendo, dessa forma, distinção entre os dois campos, pode-se dizer que o mesmo ocorre para a o desenvolvimento da crítica sobre essas produções. Levando em consideração a trajetória de Adriana Lisboa no campo literário, podemos definir sua produção como pertencente ao campo erudito, uma vez que as instâncias legitimadoras que acompanham essa trajetória são formadas por um público específico, em boa parte por integrantes das universidades e intelectuais da esfera cultural, indivíduos que constituem o sistema de produção e circulação do campo erudito.

O sistema de produção e circulação de bens simbólicos define-se como o sistema de relações objetivas entre diferentes instâncias definidas pela função que cumprem na divisão do trabalho de produção, de reprodução e de difusão de bens simbólicos. O campo de produção propriamente dito deriva sua estrutura específica da oposição - mais ou menos marcada conforme as esferas da vida intelectual e artística - que se estabelece entre, de um lado, o campo de produção erudita enquanto sistema que produz bens culturais (e os instrumentos de apropriação destes bens) objetivamente destinados (ao menos a curto prazo) a um público de produtores de bens culturais e, de outro o campo da indústria cultural especificamente organizado com vistas à produção de bens culturais destinados a não-produtores de bens culturais ("o grande público") que podem ser recrutados tanto nas frações não-intelectuais 
das classes dominantes ("o público cultivado") como nas demais classes sociais (BOURDIEU, 2013, p. 105).

O lugar que Adriana Lisboa ocupa nesse campo de produção erudita deriva também das relações que manteve nesse campo como produtora de bens culturais. As experiências e as relações adquiridas durante sua vida acadêmica, bem como de sua prática como tradutora foram de grande valia para a construção de sua imagem como escritora. Segundo Bourdieu (2013), os agentes pertencentes ao campo erudito possuem uma pretensão específica de produção que os mantêm nesse campo, ou seja, produzem para um público de pares que são seus concorrentes, o que faz com que haja um reconhecimento recíproco entre os escritores: "Afora os artistas e os intelectuais, poucos agentes sociais dependem tanto, no que são e no que fazem, da imagem que têm de si próprios e da imagem que os outros e, em particular, os outros escritores e artistas, têm deles e do que eles fazem" (BOURDIEU, 2013, p. 108).

Apesar de enquadrarmos a produção de Adriana Lisboa como erudita, devemos atentar para o fato de que as relações de produção, recepção e difusão da arte na contemporaneidade transgridem, até certo ponto, os limites que separam a arte erudita dos produtos da indústria cultural. $\mathrm{O}$ avanço tecnológico afeta diretamente a produção e comercialização da obra literária, uma vez que os canais de comunicação, como a internet, a televisão e os jornais, são os principais meios de divulgação desses produtos culturais. Novas ferramentas modificam a forma como o público interage e consome arte, diminuindo a distância entre os produtos comerciais e culturais. Os autores utilizam esses recursos para construir sua imagem e garantir seu espaço no mercado.

Como afirma Umberto Eco (2011, p. 11), "o universo das comunicações de massa é - reconheçamo-lo ou não - o nosso universo; e se quisermos falar de valores, as condições objetivas das comunicações são aquelas fornecidas pela existência [destes meios]". Seguindo a reflexão do autor, podemos ponderar que a utilização desses canais é inescapável aos intelectuais e escritores, que mesmo protestando, necessariamente acabam se utilizando dos meios de comunicação massiva. Através da utilização desses canais é possível ao escritor difundir sua produção, alcançando não apenas um campo fechado de apreciadores, mas 
tornando o acesso à sua arte mais democrático. Com isso não se pretende afirmar que os dois campos não se distinguem, mas que ambos possuem legitimidade no campo artístico e podem coexistir no interior do mesmo sistema, sem que isso represente perda de valor em cada um dos campos. Para Bourdieu (2013), o fato de coexistirem em um mesmo sistema não elimina os diferentes processos avaliativos de consagração cultural. Os dois campos de produção se opõem em termos de função e lógica de funcionamento:

\footnotetext{
Por este motivo, seus produtos derivam sua consagração desigual (ou seja, seu poder de distinção muito desigual) dos valores materiais e simbólicos com que são aquilatados no mercado de bens simbólicos, mercado mais ou menos unificado segundo as formações sociais e dominados pelas normas do mercado dominante do ângulo da legitimidade (BOURDIEU, 2013, p. 142).
}

A forma como o sistema de ensino garante legitimidade à produção de certas obras, impondo suas normas de consagração, explica como Lisboa situa-se no campo erudito, uma vez que suas obras se encaixam nas normas de consagração vislumbradas pelo sistema acadêmico. A crítica especializada reconhece a qualidade de suas obras, o que repercute em estudos sobre elas.

\section{A crítica especializada}

O desenvolvimento da indústria cultural e a expansão da cultura de massas nos fins do século XX modificaram a relação da crítica com as produções literárias. Tânia Pellegrini apresenta um panorama dessa mudança no Brasil, mostrando as diferenças entre a crítica especializada e a crítica não especializada. Para a autora, a crítica acadêmica, especializada, "funciona como um mecanismo de seleção e hierarquização da literatura, mais ou menos de acordo com os critérios do já institucionalizado" (PELLEGRINI, 1999, p. 163). Podemos acrescentar que a crítica não especializada, feita pelas revistas semanais à época, e atualmente pela internet, não possui um lugar definido, assumindo, dessa forma, um papel cada vez maior 
de propaganda, na qual o objetivo se torna pura e simplesmente a divulgação dos últimos lançamentos.

No entanto, essa crítica, cujo objetivo era informar e fazer publicidade "não impedia que se produzisse 'uma visão competente, ao mesmo tempo formativa e informativa” (PELLEGRINI, 1999, p. 164) com a profunda análise da crítica especializada, “com base em critérios de competência específicos de sua área, tais como outra linguagem e outro método de análise, muito diferentes do tratamento geralmente anedótico-biográfico conferido pelo rodapé” (PELLEGRINI, 1999, p.164). A junção das duas habilidades possibilitaria atingir o público médio, propagando as produções literárias que geralmente acabam circulando apenas no âmbito acadêmico.

O texto acadêmico pode tornar-se incompreensível para o leitor médio, que vai buscar nos blogs e sites especializados informação e material crítico sobre a produção literária difundida pelo mercado. Ao mesmo tempo, a internet se tornou responsável pela divulgação das obras e pela criação de um canal de comunicação entre autor e público. Pelegrini (1999) sugere em seu texto que falta ao campo da crítica brasileira constituir um diálogo com o novo tipo de público que se forma na contemporaneidade, aproximando a produção intelectual desse público. É possível afirmar que, ainda assim, a produção analítica das universidades é tida como referência de qualidade, possuindo papel fundamental na legitimação do produto cultural.

Determinadas apreciações a respeito da escritora Adriana Lisboa podem ser consideradas paradigmáticas entre a crítica especializada. Mesmo informações sobre vida e obra, que parecem neutras à primeira vista, envolvem uma apreciação avaliativa de sua trajetória. $\mathrm{O}$ texto que abre a entrevista que a autora concedeu ao Jornal rascunho, de setembro de 2014, é um exemplo desse viés:

Adriana Lisboa morou na França, onde foi cantora de música popular brasileira, passou algum tempo no Japão, como pesquisadora visitante no Nichibunken, em Kyoto, e vive hoje nos Estados Unidos. Sua primeira graduação foi em música, pela Uni-Rio; posteriormente, tornou-se mestre em literatura brasileira e doutora em literatura comparada pela UERJ. Estreou na literatura em 1999, com o romance Os fios da memória. Pelo segundo romance, Sinfonia em branco (2001), recebeu o Prêmio José Saramago e foi apontada pela crítica como uma das mais importantes 
revelações da nova literatura brasileira. [...] Como novelista, publicou $O$ coração às vezes para de bater. Seus livros já foram traduzidos para o inglês, francês, espanhol, alemão, italiano, romeno, sueco e sérvio. ${ }^{1}$

O entusiasmo em relação à obra de Adriana Lisboa é evidente. O primeiro traço destacado é seu cosmopolitismo. Adriana Lisboa é apresentada como cidadã do mundo, adaptada a diversas culturas. O texto destaca que, na França, Lisboa atuou como cantora, e que sua estada no Japão relacionou-se com seu papel de pesquisadora-visitante, dados que remetem às motivações de suas viagens. Em seguida, o texto ressalta sua formação acadêmica, com graduação em música e um percurso de pós-graduação em Literatura. $\mathrm{O}$ acréscimo desses dados, por um lado, reforça a motivação de seu cosmopolitismo, e por outro, acrescenta uma nova apreciação relacionada à sua capacidade intelectual. A forma como os dados estão encadeados sugere certa linearidade e coerência em sua trajetória. Seu ingresso no campo literário é informado com a data e o título do primeiro romance. A publicação do segundo, com data bastante próxima, liga-se ao recebimento de um prêmio importante, o que configura um reconhecimento imediato do valor de sua obra. O lugar no campo literário conquistado por Lisboa, além de imediato, é naturalizado pelo trecho: "apontada pela crítica como uma das mais importantes revelações da nova literatura brasileira.” Temos aí um juízo de valor que vai se tornando referência tanto para a crítica especializada, quanto para a não especializada. Traduzida para diversas línguas, a imagem de escritora de sucesso internacional retoma o cosmopolitismo das informações biográficas iniciais.

A interpretação desse trecho revela uma tópica concernente a Lisboa que é reiteradamente utilizada pela imprensa, pelos comentadores e pela crítica. A diversidade cultural é um dos aspectos que aparecem nas narrativas de Adriana Lisboa, já que seus livros têm personagens com valores diversificados e que protagonizam experiências cotidianas, mas também refletem as vivências da autora a partir de suas leituras de mundo.

A obra de estreia de Adriana Lisboa, Os Fios da Memória (1999), flerta com o romance histórico e desenvolve-se em narrativas fragmentadas e não lineares.

\footnotetext{
${ }^{1}$ Disponível em: <http://rascunho.com.br/eterna-curiosidade >. Acesso em 11/07/2018.
} 
Um exemplo desse processo é a compreensão humana de eventos passados como, por exemplo, a história do Brasil colonial. Frequentemente, em suas narrativas, a autora desenrola o texto de maneira reflexiva e atenta aos pequenos detalhes. Nesse romance, Lisboa apresenta as inquietudes da personagem Beatriz Brasil que, ao receber como herança a casa de seus tios no bairro do Cosme Velho, Rio de Janeiro, descobre alguns diários antigos escritos por seus antepassados portugueses e africanos. Trata-se, portanto, de uma obra centrada na dimensão psicológica das personagens. Percebemos também que sua escrita preza pelo poético, com uma sensibilidade singular. Tal característica permanecerá em outras narrativas de Lisboa:

[...] abrindo seu próprio caminho através da construção de uma voz ("E é isso o que busco: a minha voz, sem qualquer outro tipo de compromisso. A minha voz é tudo o que eu tenho a oferecer"), que não pretende inovar ou impor um estilo, a autora investe na elegância, traduzida pela convivência do simples com o refinado, na memória como uma interface capaz de lembrar outras temporalidades, outras cadências de leitura e escrita, e na descrição do detalhe (AZEVEDO, 2004, 123).

No livro Ficção brasileira contemporânea (2009), Karl Erik Schollhammer realiza uma reflexão sobre a obra de Adriana Lisboa, apontando o sucesso da escritora e sua obra: "Uma outra voz, muito diferente, mas que também coloca no centro de sua criatividade o diálogo com a literatura, pertence a Adriana Lisboa" (SCHOLLHAMMER, 2009, p. 96).

A trama de Sinfonia em Branco (2001), segundo romance da autora, dá-se por meio de recuos no tempo e de lembranças que resgatam um episódio trágico vivenciado por Clarice e Maria Inês. Tal acontecimento é representado através das consequências psicológicas do abuso sexual sofrido por Clarice e das omissões de sua própria mãe. Nesse romance, chama atenção o jogo entre a leveza da enunciação e o tema da violência sexual. Esse jogo, concebido na obra como elemento estético, é revelador de certa melancolia. As personagens acabam imensas em uma zona em que memória e tempo presente aparecem entrelaçados. Sobre esse efeito, Luciene Azevedo, em sua tese de doutorado, observa que:

[...] a narrativa acrescenta ao jogo com as diversas temporalidades da 
memória uma importância ao detalhe que pulveriza a tensão preparatória de um clímax. A história contada sem nenhuma urgência, tal como em Os Fios da Memória, investe em um realismo das coisas mínimas, quase imperceptíveis. E se pode soar incongruente que uma nuance realista seja introduzida em uma narrativa em que a dominante é a memória, essa é a grande diferença da prosa de Adriana Lisboa (AZEVEDO, 2004, p.124).

Percebemos que Adriana Lisboa mitiga o impacto da violência proposta no tema do romance em função da delicadeza com que a história é narrada. Podemos acrescentar que a obra contém referências significativas ao romance $A$ morte em Veneza, de Thomas Mann (1971). Trata-se, portanto, de uma narrativa que convoca o leitor a exercer suas capacidades interpretativas, decifrando os segredos que são revelados ao longo das páginas.

$\mathrm{Na}$ linguagem técnica da crítica acadêmica, um dos aspectos que sobressaem nas produções de Lisboa é a forma poética com que tece as situações do cotidiano. Sua literatura pode ser considerada intimista, no sentido de explorar o tempo psicológico das personagens, mas tem a singularidade de aprofundar suas emoções e sentimentos em direção aos aspectos sociais e políticos que as envolvem. Das características citadas nos trabalhos perscrutados para a análise, destacam-se também as reflexões existenciais tematizadas pelos romances e o modo como algumas obras exploram a construção da identidade do sujeito contemporâneo.

Suas personagens carregam características que escapam do usual, com diferentes idades e de universos distintos. $\mathrm{O}$ mesmo ocorre com a ambientação de seus romances que, em muitos casos, se passam em lugares diferentes. Essa experimentação, carregada de informação e diversidade, caracteriza o período em que vivemos, que segundo Terry Eagleton,

[...] vê o mundo como contingente, gratuito, diverso, instável, imprevisível, um conjunto de culturas ou interpretações desunificadas gerando um certo grau de ceticismo em relação à objetividade da verdade, da história e das normas, em relação às idiossincrasias e a coerência de identidades (EAGLETON, 1998, p. o6).

Podemos observar em seus romances as articulações que exploram a construção da identidade do sujeito contemporâneo, tanto no nível do conteúdo 
quanto no nível estrutural. Sua obra tem sido definida por alguns estudiosos como pós-moderna, resgatando a carga literária do modernismo, mas não como uma forma de reviver o estilo, senão de reescrevê-lo: "A ficção pós-moderna não seria, portanto, uma ficção do contra, pautada pela negatividade modernista, mas ao contrário, uma ficção guiada sobretudo pela reescritura - inclusive de textos modernistas" (CARNEIRO apud DIAS, 2011, p. 40).

O romance Um beijo de colombina (2003), por exemplo, nada mais é do que o resgate de uma obra moderna, mais especificamente de Estrela da vida inteira (1966), de Manuel Bandeira. Essa obra de Lisboa, ao revisitar os versos de Bandeira, faz uso da intertextualidade para construir um romance metaficcional. Conforme definição de Larry McFerry, o romance metaficcional é "um metateorema narracional cujo tema principal é o próprio sistema ficcional e os moldes pelos quais a realidade é padronizada segundo as convenções narrativas”2 (McCAFERRY, 1982, p. 19).

O romance Rakushisha (2007) incorpora elementos da arte poética de Matsuo Bashô, e Azul-corvo (2010), por sua vez, estabelece um jogo de referências com a poesia de Marianne Moore. O constante diálogo da autora com o universo literário não ocorre por acaso, e suas referências não estão incluídas no texto de forma aleatória. Como em outras obras contemporâneas, esses referenciais constituem um adendo comunicativo, proporcionando uma comunicação maior entre o leitor e o texto.

A crítica especializada, ao investigar o processo criativo de Adriana Lisboa, chama atenção para a influência da música e da poesia em sua escrita, e também para a representação do cotidiano em seus textos. Esses dois aspectos estão interrelacionados e configuram uma certa delicadeza de seu estilo. A transformação da vida cotidiana em ficção é recorrente em sua obra e está ligada à própria experiência da autora: "Para mim, é muito importante aquilo que vejo. Tenho muita dificuldade para escrever sobre o que não vejo”3 (LISBOA, 2011, n.p).

\footnotetext{
${ }^{2}$ Tradução livre do trecho original em inglês: "[...] a narrational metatheorem whose subject matter is fictional systems themselves and the molds through which reality is paterned by narrative convention".

${ }^{3}$ Disponível em: http://rascunho.com.br/adriana-lisboa/. Acesso em 11/07/2018. 
O que a crítica identifica como literatura da delicadeza está relacionado também com o cuidado que a autora demonstra com a norma culta da língua. Em sua tese de doutorado Estratégias para enfrentar o presente, a pesquisadora Luciene Azevedo (2004) apresenta a hipótese de que a "ideia-força" da leveza está presente na literatura contemporânea, de forma que a vertente da delicadeza encontra terreno nos textos de muitos autores. Analisando a obra de Adriana Lisboa, a pesquisadora destaca que:

[...] sua escolha pelo anti-pop, pela negação de uma forte vertente neonaturalista na literatura contemporânea pretende reverter os paradigmas de uma estética que a autora considera bem aceita pela mídia. Se o exercício de elegância que são seus romances não se impõe ostensivamente contra qualquer tendência, a sua presença no panorama atual da prosa brasileira tem como linha de fuga o seu avesso sempre presente. (AZEVEDO, 2004, p. 124).

O jornalista e escritor José Castello também relaciona a delicadeza ao estilo da autora. Ao analisar o romance Azul-corvo, Castello demonstra como "a delicadeza leva Adriana Lisboa a manipular o tempo como se ele fosse um velho cuco que, por defeito, por vício, por magia, registrasse horas diferentes e simultâneas" (VASSALO, 2011, n.p). A questão da delicadeza nos textos de Adriana Lisboa também está presente nos estudos de Denilson Lopes:

A delicadeza não é, portanto, só um tema, uma forma, mas uma opção ética e política, traduzida em recolhimento e desejo de descrição em meio à saturação de informações [...] O sublime no banal. A leveza no cotidiano. Eclipse do sujeito, do autor diante do mundo (LOPES, 2007, p. 18).

Apresentando ao leitor as características que ligam a obra ao poético, o autor enfatiza: "Nada de trágico, épico, mas um certo tom elevado, sério, que tira beleza do pequeno" (LOPES, 2007, p. 22).

Adriana Lisboa manifestou certa reserva com o uso do termo delicadeza para caracterizar sua literatura:

[...] eu olho com certo pudor para essa palavra "delicadeza". Acho importante não tingir esse conceito com algo no sentido da fragilidade e da ligeireza (e portanto da superficialidade e da inconsistência). De todo 
modo, a delicadeza nunca foi um projeto estético ou de vida para mim, e muitas vezes não me identifico com o que dizem sobre o meu trabalho ou sobre mim, nesse sentido. Eu escolheria como norte antes a gentileza, o respeito, a dedicação, a humildade. E a leveza, no sentido em que a tomou Italo Calvino. Talvez esses valores, quando reunidos num saco, possam apontar para uma impressão de delicadeza genérica. Meu convívio com os haikais japoneses me ensinou a buscar uma postura estética que tem mais a ver com o não preenchimento de espaços vazios. Também penso numa espécie de "desdramatização do drama”, que seria retirar do texto o peso narrativo das situações que já são por si pesadas. Mas isso não é para torná-las mais palatáveis ou bonitas: é apenas porque a contenção e a sugestão podem ser mais eloquentes do que os berros. É como manter uma corda tensa. Na minha vida cotidiana, talvez uma tentativa de tornar consciente e respeitosa minha relação com o outro (pessoas, bichos, objetos) dê a impressão de que sou uma pessoa delicada. Eu diria apenas que sou - ou procuro ser - atenta (LISBOA apud VASSALO, 2011, n.p).

Os argumentos de Lisboa, ao observar que sua postura estética tem a ver com o não preenchimento de espaços vazios e com a forma "desdramatizada" com que conduz suas narrativas, sinalizam sua posição como observadora privilegiada de sua própria obra. Nesse sentido, podemos entender seus comentários como apreciação crítica de seus processos construtivos.

Um outro aspecto evidenciado pela crítica na obra de Adriana Lisboa é sua propensão a tematizar viagens, mudanças e deslocamentos. Em Azul-corvo (2010), Adriana Lisboa tematiza viagens e mudanças. O romance conta a história de uma adolescente de treze anos, Evangelina (também chamada de Vanja), que, após o falecimento da mãe, muda-se do Brasil para os Estados Unidos para viver com o ex-padrasto. $\mathrm{O}$ verdadeiro intuito de sua mudança, no entanto, é encontrar o pai biológico. Durante essa busca, a personagem Vanja recorda-se de acontecimentos do passado, especialmente aqueles que se referem à própria mãe. Através dessa trama, o leitor entra em contato com questões históricas referentes à guerrilha do Araguaia e mescla ficção e realidade. Os fatos apresentados em um contexto ficcional fazem parte de um imaginário coletivo, do qual a autora se apropria para dar mais verossimilhança à história narrada.

Certamente por ter residido por determinado período na França e morar no estado do Colorado, nos Estados Unidos, desde 2007, Adriana Lisboa, com base na própria vivência como imigrante, apresenta, com certa regularidade em suas narrativas, a sensação de desconexão ou deslocamento de personagens expatriados 
ou que se consideram estrangeiros, independentemente do lugar. Segunda a própria autora, essa possibilidade de estar em lugares diversos é essencial para uma compreensão mais universalista, como bem notou em entrevista à Suzana Uchôa Itiberê: "Minha mudança para os Estados Unidos foi inesperada, mas muito bemvinda porque, mais uma vez, me expôs a uma novidade, a uma cultura e um local desconhecidos" (LISBOA, 2010, s/p). A análise da crítica especializada, apesar da especificidade da linguagem que utiliza - aspecto que afasta o leitor comum da compreensão teórica sobre literatura -, ainda é considerada referência crítica devido à seriedade das abordagens e ao aprofundamento das análises. E isso, de certa forma, atribui legitimidade às produções que são analisadas positivamente, como é o caso da produção de Adriana Lisboa.

O trânsito de Lisboa entre acadêmicos e demais teóricos também contribuiu para a legitimação de sua obra. Podemos entender as relações da autora no meio acadêmico como uma eficiente estratégia de profissionalização, capaz de alavancar a difusão e a comercialização de suas obras.

\section{A crítica não especializada}

Quanto à crítica não especializada, podemos reportar uma quantidade considerável de resenhas e textos sobre suas obras e sobre sua participação no campo literário. Porém, os textos destinam-se à divulgação e não à análise das obras, como ocorre por parte da crítica especializada. Grande parte dessas apreciações dedica-se a comentar suas obras, sem aprofundar os elementos basilares que a constituem. Nota-se que o foco dessas resenhas é provocar interesse no leitor para que consuma o produto cultural, o que não deve ser visto como algo ruim, pelo contrário, pois esse estímulo, resultado da linguagem contagiante e dos textos curtos dos jornalistas, agrega reconhecimento para a autora fora do nicho intelectual, atingindo públicos diversos. Da mesma forma, a crítica não especializada, ao produzir ensaios e resenhas sobre as obras, aproxima o leitor dessas produções. 
Por meio da leitura de resenhas de jornais, de revistas e de blogues, verificou-se que o foco dos textos recai principalmente sobre a trama, expondo o enredo e não os aspectos estruturais ou técnicos das obras. O gênero resenha de obras literárias contempla a apresentação do autor, o resumo da obra e um comentário avaliativo do texto. Alguns aspectos da obra literária de Adriana Lisboa são recorrentemente lembrados: a simplicidade, a poeticidade e a narração do cotidiano.

Muitos veículos da chamada grande imprensa, como Folha de S. Paulo ${ }^{4}, \mathrm{O}$ Globo5, Isto É ${ }^{6}$ e O Estado de S. Paulo7, publicaram matérias, entrevistas e resenhas sobre a trajetória da escritora e suas obras. Além desses veículos de imprensa, contas em plataformas digitais, como YouTube e Instagram e sites relacionados a instituições culturais e editoras, como $\operatorname{Sesc}^{8}$, TV Cultura9 ${ }^{9}$ Saraiva ${ }^{10}$, entre outros, publicam textos e vídeos que promovem as produções de Lisboa.

Além disso, a participação da escritora em eventos, a realização de oficinas, as entrevistas concedidas aos diversos meios de comunicação ligados à cultura, incidem sobre sua imagem pública, contribuindo para sua difusão no mercado editorial e para sua profissionalização.

As diferentes situações que se sucedem na vida de um autor permitem com que ele opte por adotar diferentes estratégias para obter êxito e visibilidade no campo literário. No caso de Adriana Lisboa, a proximidade de certos agentes levoua a vivenciar experiências que certamente realçaram sua trajetória. Como a carreira da escritora vem se consolidando cada vez mais, a quantidade de críticas sobre sua

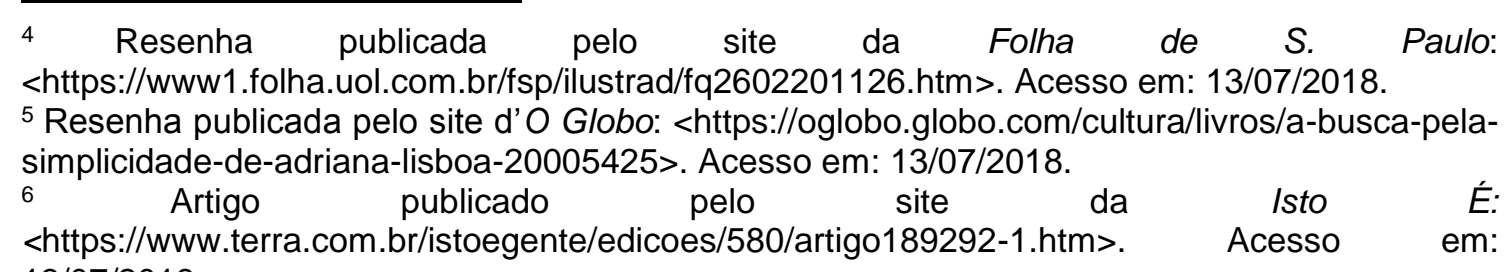
13/07/2018.

7 Artigo publicado pelo site do Estado de $S$. Paulo: <https://cultura.estadao.com.br/noticias/literatura,adriana-lisboa-escreve-poemas-de-paixao-elucidez,1582127>. Acesso em: 13/07/2018.

8 Vídeo postado pela TV Sese: <https://www. youtube.com/wateh? $v=t A 3 y o M F 3 k b 4>$. Acesso em: 13/07/2018.

9 Vídeo postado pela TvCultura Digital: <<https://www.youtube.com/watch?v=sIMCn7FeZ14>> Acesso em: 13/07/2018.

10 Vídeo publicado pela editora Saraiva: <<https://www.youtube.com/watch?v=7dlt-qartxw >> Acesso em: 13/07/2018. 
obra tem aumentado, o que garante que seu trabalho seja divulgado junto ao público leitor. Nesse contexto, críticos, jornalistas e blogueiros tornaram-se peças fundamentais na construção da sua imagem pública. São eles que fabricam diversas conjecturas e formulações possíveis para cada texto.

Certos críticos acompanharam o desenvolvimento da carreira de Adriana Lisboa, tornando pública sua estratégia de profissionalização, indicando e valorizando as instituições às quais ela se ligou, criando no público em geral diversas expectativas futuras em relação a seus livros. Na construção da imagem pública estão envolvidos mecanismos diversos, como, por exemplo, participação em eventos literários, lançamentos em grandes livrarias e aparições na imprensa, entre outros. Paralelamente essas práticas se convertem em efeitos de consagração, uma vez que autores ou obras eleitas pela crítica acabam ganhando espaço em livros, revistas, artigos acadêmicos, entre outros.

A forma como a escritora se relaciona com os meios de comunicação, principalmente com as novas plataformas digitais, além de ajudar a divulgar sua produção, contribui para sua imagem como escritora, ou seja, isso tem estimulado a produção da crítica não especializada a seu respeito.

Conforme mencionamos anteriormente, tanto as críticas especializadas quanto não especializadas interagem no interior do mesmo sistema e muitas vezes são veiculadas pelos mesmos meios. Ao mesmo tempo em que um jornal publica uma resenha sobre um best-seller, pode apresentar na coluna ao lado um texto de um autor renomado da "alta cultura". A trajetória de Adriana Lisboa tem sido contemplada por ambas as críticas, com avaliações positivas de sua obra.

\section{Referências}

AZEVEDO, Luciene. Estratégias para enfrentar o presente: a performance, o segredo e a memória. 2004. Tese de doutoramento (Literatura comparada) Instituto de Letras, UERJ, Rio de Janeiro, 2004.

BOURDIEU, Pierre. A economia das trocas simbólicas. São Paulo: Perspectiva, 2013. 
DIAS, João Paulo M. Costurando os retalhos: Um beijo de colombina, de Adriana Lisboa. In: Fórum de Literatura Brasileira Contemporânea 3. UFRJ, Editora Torre, 2011. Disponível em: http://www.forumdeliteratura.com.br/artigos/artigos-3edicao/15-costurando-os-retalhos-um-beijo-de-colombina-de-adriana-lisboa.

Acesso em: 6 jan. 2018.

EAGLETON, Terry. As ilusões do pós-modernismo. Tradução: Elisabeth Barbosa, Rio de Janeiro: Jorge Zahar, 1998.

ECO, Umberto. Cultura de massa e "níveis" de cultura. In: . Apocalípticos e Integrados. São Paulo: Perspectiva, 2011, p. 33-65.

LISBOA, Adriana. Azul-corvo. Rio de Janeiro: Rocco, 2010. . Rakushisha. Rio de Janeiro: Rocco, 2007. . Um beijo de colombina. Rio de Janeiro: Rocco, 2003. . Sinfonia em branco. Rio de Janeiro: Rocco, 2001 . Os fios da memória. Rio de Janeiro: Rocco, 1999.

LISBOA, Adriana. Paiol Literário. Jornal Rascunho, Curitiba, n. 217, nov. 2011. Acesso em: Disponível em: <http://rascunho.com.br/adriana-lisboa/>. LISBOA, Adriana. Adriana Lisboa. [Entrevista concedida a] Suzana Uchôa Itiberê. Disponível em: < https://www.terra.com.br/istoegente/edicoes/580/artigo1892921.htm>. Acesso em: Acesso em: 9 jul. 2018.

LOPES, Denílson. A delicadeza: estética, experiência e paisagens. Brasília: Ed. UNB, 2007.

LUKÁCS, George. O romance como epopéia burguesa. Revista Ensaios Ad Hominem, n. 1, tomo II. São Paulo: Estudos e Edições Ad Hominem, 1999.

McCAFERRY, Larry. The metaficcional muse: the works of Robert Coover, Donald Barthelme, and William Gass. Pitsburgh: University of Pittsburgh Press, 1982. PELLEGRINI, Tânia. A imagem e a letra: aspectos da ficção brasileira contemporânea. São Paulo: Mercado de Letras, 1999.

SCHOLLHAMMER, Karl Erik. Ficção brasileira contemporânea. Rio de Janeiro: Civilização Brasileira, 2009.

VASSALO, Márcio. Adriana Lisboa - com leveza e profundidade. Notícias e entrevistas. Site Agência Riff. 27 out. 2011. Disponível em: 
BRINO, NEILA BRASIL

<http://www.agenciariff.com.br/site/NoticiaEntrevista/ShowEntrevista/33>.

Acesso em: 12 fev. 2018.

* Doutoranda do Programa de Pós-Graduação em Letras: Literatura e Cultura, da Universidade Federal da Bahia. 